\title{
Características fenotípicas dos pacientes com anemia falciforme de acordo com os haplótipos do gene da $\boldsymbol{\beta}^{\mathrm{s}}$-globina em Fortaleza, Ceará Phenotypic characteristics of patients with sickle cell anemia related to $\beta^{S}$-Globin gene haplotypes in Fortaleza, Ceara
}

Lilianne B. Silval

Romélia P. Gonçalves ${ }^{2}$
Foram analisados 47 pacientes com diagnóstico clínico, laboratorial e molecular de anemia falciforme, residentes em Fortaleza, Ceará, com a finalidade de fornecer informações sobre a influência dos haplótipos do gene da $\beta^{S}$ - globina nas características fenotípicas desta doença. A determinação dos valores hematológicos foi realizada em contador automático de células sanguíneas, e os níveis de HbF foram determinados pela técnica da desnaturação alcalina. O DNA foi isolado de leucócitos, a partir de

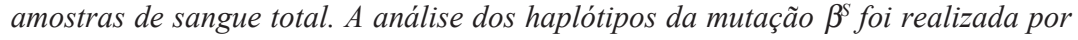
PCR-RFLP (Polymerase Chain Reaction-Restriction Fragment Lenght Polymorphism), sendo analisados seis sítios polimórficos de restrição. Os pacientes foram divididos em cinco grupos, de acordo com o tipo de haplótipo: Bantu/Bantu, Benin/Benin, Bantu/ Benin, Bantu/Atípico e Benin/Atípico. O nível de significância considerado nas análises foi $p<0,05$. Na comparação entre os haplótipos e as características hematológicas estudadas, apenas os valores de HbF e Ht apresentaram diferença estatisticamente significativa. Os níveis de HbF foram maiores no haplótipo Benin, seguido do haplótipo Bantu, o que está em conformidade com os dados da literatura. Foram demonstrados maior presença de crises vaso-oclusivas e episódios de pneumonia no haplótipo Benin/ Atípico do que no haplótipo Bantu/Atípico; e maior presença de crises de infecção urinária no haplótipo Benin/Atípico do que no haplótipo Benin/Benin. Não houve diferença estatisticamente significativa entre os haplótipos Bantu/Bantu e Benin/Benin em relação às complicações clínicas; entretanto, foi observado que o haplótipo Bantu/ Bantu tem uma maior frequência em todos os eventos clínicos estudados quando comparado ao Benin/Benin. Os resultados demonstram que o tipo de haplótipo do gene da $\beta^{S}$-globina influencia as características fenotípicas dos pacientes com anemia falciforme, portanto a utilização de técnicas moleculares para a detecção do haplótipo envolvido deve ser considerada como uma importante ferramenta diagnóstica para prever o quadro clínico destes pacientes. Rev. Bras. Hematol. Hemoter.

Palavras-chave: Anemia falciforme; fenótipo; prognóstico; genética.

\section{Introdução}

A anemia falciforme é o resultado de uma mutação pontual $(\mathrm{GAG} \rightarrow \mathrm{GTG})$ no códon do gene da globina $\beta$, conduzindo a uma substituição de ácido glutâmico por valina na sexta posição da cadeia polipeptídica. ${ }^{1}$ É caracterizada pela homozigose da hemoglobina $\mathrm{S}(\mathrm{SS}){ }^{2}$

O tipo de variabilidade mais comum no complexo gênico da globina beta é aquele produzido por variações de sequências que alteram o sítio de reconhecimento de uma enzima de

${ }^{I}$ Farmacêutica bioquímica.

${ }^{2}$ Farmacêutica. Professora associada da Universidade Federal do Ceará - Fortaleza-CE

Universidade Federal do Ceará Fortaleza-CE

Correspondência: Lilianne Brito da Silva

Rua Dr. José Lourenço, 1820 Apto.502 - Aldeota

60115-281-Fortaleza-CE - Brasil

E-mail: liliannebrito@hotmail.com 
restrição. Usando uma série de enzimas de restrição que identificam alterações específicas no DNA, é possível identificar a constituição das regiões adjacentes ao lócus beta. Através da técnica da reação em cadeia mediada pela polimerase para polimorfismo dos comprimentos dos fragmentos de restrição (PCR- RFLP) é possível determinar o padrão de combinação dos sítios polimórficos para qualquer cromossomo, sendo este chamado de haplótipo. ${ }^{3}$

O tipo de haplótipo associado ao gene da HbS têm importância na gravidade clínica da anemia falciforme, estando relacionado a um quadro clínico e níveis de $\mathrm{HbF}$ variados. ${ }^{4,5,6} \mathrm{O}$ haplótipo Senegal está associado a níveis elevados de $\mathrm{HbF}(>15 \%)$ e curso clínico menos grave da doença; o Benin, a níveis medianos de $\mathrm{HbF}$ ( $5 \%$ a $15 \%$ ) e curso clínico intermediário; o Bantu ou República Centro Africana, a níveis diminuídos de $\mathrm{HbF}(<5 \%)$ e quadro clínico mais grave; e o haplótipo Árabe-Indiano, que apresenta níveis elevados de $\mathrm{HbF}$ e curso clínico heterogêneo. ${ }^{7,8}$

Os haplótipos da anemia falciforme são classificados em cinco tipos diferentes, de acordo com a origem étnica e geográfica onde predominam. O haplótipo Benin (BEN) tem sido associado à África Ocidental; o Bantu ou República Centro Africana (CAR) à África Oriental e Centro-Sul; o Senegal à África Atlântico-Ocidental; o Árabe-Indiano à Índia e Península Arábica e o Camarões à Costa Ocidental Africana. ${ }^{1,7,9}$

A maioria dos cromossomos com o gene $\beta^{\mathrm{S}}$ tem um dos cinco haplótipos comuns, contudo existe uma minoria de cromossomos, aproximadamente $5 \%$, que estão associados com haplótipos menos comuns, geralmente designados como haplótipos atípicos. ${ }^{10}$ Segundo Zago et al., ${ }^{11}$ os haplótipos atípicos são produzidos por diversos mecanismos genéti$\cos$, sendo a recombinação entre dois haplótipos $\beta^{\mathrm{s}}$ típicos o mais comum.

O presente estudo teve como objetivo analisar a influência dos haplótipos do gene da $\beta^{\mathrm{S}}$-globina nas características fenotípicas da anemia falciforme.

\section{Casuística e Método}

Trata-se de um estudo corte transversal em 47 pacientes com diagnóstico clínico, laboratorial e molecular de anemia falciforme (forma homozigótica SS), atendidos no ambulatório do serviço de Hematologia de um hospital de referência em Fortaleza, capital do Ceará, todos voluntários, de ambos os sexos. Foram excluídos do estudo os pacientes que receberam transfusão sanguínea nos últimos três meses antes da coleta e os que faziam uso de hidroxiureia ou qualquer medicação que estimule a síntese de hemoglobina fetal. O consentimento informado foi obtido de todos os indivíduos e o estudo foi submetido e aprovado pelo Comitê de Ética da Universidade Federal do Ceará.

A determinação dos valores hematológicos foi realizada em contador automático de células sanguíneas (modelo Sysmex KX-21N, Roche). A determinação da concentração de hemoglobina fetal foi realizada pelo método de desnaturação alcalina. ${ }^{12}$

O DNA foi isolado de leucócitos, a partir de amostras de sangue total, seguindo o protocolo de Sambrook et al. ${ }^{13} \mathrm{~A}$ análise dos haplótipos da mutação $\beta^{\mathrm{S}}$ foi realizada por meio da técnica da reação em cadeia mediada pela polimerase para polimorfismo dos comprimentos dos fragmentos de restrição (PCR-RFLP), sendo analisados seis sítios polimórficos de restrição, seguindo a metodologia de Sutton et al. ${ }^{14}: 1$. XmnI $5^{\prime} \gamma^{\mathrm{G}}, 2$. Hind III $\gamma^{\mathrm{G}}, 3$. Hind III $\gamma^{\mathrm{A}}, 4$. Hinc II $\psi \beta \beta$, 5. Hinc II $3^{\prime} \psi \beta$, 6. Hinf I 5' $\beta$.

Os pacientes foram divididos em cinco grupos, de acordo com o tipo de haplótipo: Bantu/Bantu, Benin/Benin, Bantu/ Benin, Bantu/Atípico e Benin/Atípico.

\section{Análise estatística}

O GraphPad Prism (versão 5.0) foi o programa utilizado para a realização da análise estatística. O teste utilizado para avaliação da distribuição normal das variáveis contínuas foi o Kolmogorov-Smirnov. O teste ANOVA foi utilizado para a comparação múltipla de médias entre os haplótipos e os valores de $\mathrm{HbF}, \mathrm{He}, \mathrm{Hb}, \mathrm{Ht}$, leucócitos e plaquetas; e o pósteste Newman-Keuls para identificar quais grupos foram diferentes. O teste exato de Fisher foi utilizado na comparação de proporções entre os haplótipos e as complicações clínicas dos pacientes. O nível de significância estatística considerado na análise foi $\mathrm{p}<0.05$.

\section{Resultados}

Os valores hematológicos de todos os pacientes do estudo estão representados na Tabela 1. Apenas a concentração de HbF não apresentou distribuição normal em seus valores.

A comparação múltipla de médias entre os cinco haplótipos apresentou diferença estatisticamente significativa apenas para os valores de $\mathrm{HbF}(\mathrm{p}=0,0018)$ e $\mathrm{Ht}(\mathrm{p}=0,0298)$. Após a utilização do pós-teste estatístico foi observada diferença em relação à $\mathrm{HbF}$ entre os grupos Bantu/Bantu $(6,14 \pm$ $3,46) \times$ Bantu/Atípico $(10,88 \pm 2,78)(\mathrm{p}<0,05)$, Benin/ Benin $(8,56 \pm 1,93) \times$ Benin/Atípico $(1,43 \pm 1,17)(\mathrm{p}<0,05)$, Bantu/

Tabela 1. Valores médios e desvio-padrão das análises hematológicas realizadas em pacientes com anemia falciforme

\begin{tabular}{cccccc}
\hline $\mathrm{HbF}(\%)$ & $\begin{array}{c}\mathrm{He} \\
(\times 10 \% / \mathrm{L})\end{array}$ & $\begin{array}{c}\mathrm{Hb} \\
(\mathrm{g} / \mathrm{dl})\end{array}$ & $\begin{array}{c}\mathrm{Ht} \\
(\%)\end{array}$ & $\begin{array}{c}\text { Leucócitos } \\
(\times 10 \% / \mathrm{L})\end{array}$ & $\begin{array}{c}\text { Plaquetas } \\
(\times 10 \% / \mathrm{L})\end{array}$ \\
\hline $6,72 \pm 3,73$ & $2,74 \pm 0,60$ & $8,50 \pm 1,30$ & $25,20 \pm 3,96$ & $11.20 \pm 3.41$ & $421.457 \pm 108.273$ \\
\hline
\end{tabular}

Fonte: Dados da pesquisa, 2009.

$\mathrm{HbF}$; hemoglobina fetal; He: hemácias; Hb: hemoglobina; Ht: hematócrito 
Tabela 2. Características hematológicas dos pacientes de acordo com o haplótipo da anemia falciforme

\begin{tabular}{ccccccc}
\hline & Bantu/Bantu & Benin/Benin & Bantu/Benin & Bantu/Atípico & Benin/Atípico & Valor de $p$ \\
\hline $\mathrm{HbF}(\%)$ & $6,14 \pm 3,46$ & $8,56 \pm 1,93$ & $6,47 \pm 3,59$ & $10,88 \pm 2,78$ & $1,43 \pm 1,17$ & $\mathrm{p}=0,0018$ \\
$\mathrm{He}$ & $2,79 \pm 0,53$ & $2,97 \pm 0,26$ & $2,35 \pm 0,43$ & $2,58 \pm 0,45$ & $2,95 \pm 0,64$ & $\mathrm{p}=0,07$ \\
$\left(\mathrm{x} 10^{9} / \mathrm{L}\right)$ & $8,65 \pm 1,10$ & $8,58 \pm 0,37$ & $7,82 \pm 1,09$ & $8,02 \pm 1,04$ & $9,18 \pm 1,49$ & $\mathrm{p}=0,1668$ \\
$\mathrm{Hb}(\mathrm{g} / \mathrm{dl})$ & $25,98 \pm 2,86$ & $25,46 \pm 1,22$ & $22,54 \pm 3,19$ & $23,73 \pm 3,48$ & $26,76 \pm 4,05$ & $\mathrm{p}=0,0298$ \\
$\mathrm{Ht}(\%)$ & $8,826 \pm 2,068$ & $11,349 \pm 4,296$ & $12,515 \pm 3,102$ & $8,660 \pm 2,248$ & $\mathrm{p}=0,1673$ \\
$\begin{array}{c}\text { Leucócitos } \\
\left(\times 10^{9} / \mathrm{L}\right)\end{array}$ & $11,989 \pm 2,849$ & & & & \\
$\begin{array}{c}\text { Plaquetas } \\
\left(\mathrm{x} 10^{9} / \mathrm{L}\right)\end{array}$ & $438,047 \pm 91,560$ & $398,500 \pm 75,347$ & $376,727 \pm 109,609$ & $495,833 \pm 80,576$ & $432,666 \pm 204,020$ & $\mathrm{p}=0,2162$ \\
\hline
\end{tabular}

Fonte: Dados da pesquisa, 2009.

Os resultados foram reportados em valores de Média \pm Desvio-padrão. Foi utilizado o teste ANOVA para a comparação múltipla de médias entre os haplótipos (Bantu/Bantu, Benin/Benin, Bantu/Benin, Bantu/Atípico, Benin/Atípico) e os valores de HbF, He, Hb, Ht, Leucócitos e Plaquetas. Foi utilizado o pós-teste Newman-Keuls para identificar quais grupos foram diferentes.

HbF: Hemoglobina fetal; He: Hemácias; Hb: Hemoglobina;Ht: Hematócrito

$\operatorname{Benin}(6,47 \pm 3,59) \times$ Bantu/Atípico $(10,88 \pm 2,78)(\mathrm{p}<0,05)$ e Bantu/Atípico $(10,88 \pm 2,78)$ x Benin/Atípico $(1,43 \pm 1,17)$ $(p<0,01)$. Em relação ao $\mathrm{Ht}$ foi observada diferença entre os grupos Bantu/Bantu $(25,98 \pm 2,86) \times$ Bantu/Benin $(22,54$ $\pm 3,19)(\mathrm{p}<0,05)$ (Tabela 2 e Gráfico 1).

Os pacientes com o haplótipo Bantu/Atípico obtiveram menor presença de crises vaso-oclusivas e episódios de pneumonia quando comparados aos pacientes com o haplótipo Benin/Atípico. Crises de infecção urinária foram mais frequentes nos pacientes com o haplótipo Benin/Atípico do que nos pacientes com o haplótipo Benin/Benin. Todas as outras comparações entre os haplótipos e a presença de complicações clínicas não obtiveram diferença estatisticamente significativa (Tabela 3 ).

\section{Discussão}

Em relação aos valores hematológicos dos pacientes estudados, apenas a concentração de $\mathrm{HbF}$ não apresentou distribuição normal em seus valores, mostrando que não há uma distribuição simétrica nos resultados. A média da concentração de hemoglobina fetal no presente estudo foi de $6,72 \pm 3,73$ (Tabela 1). Os resultados foram semelhantes aos demais estudos da literatura. A concentração média de $\mathrm{HbF}$ encontrada por Queiroz ${ }^{15}$ foi de 6,45\%; Figueiredo et al. ${ }^{16}$ encontraram uma $\mathrm{HbF}$ de 6,35\%; Galiza Neto et al. ${ }^{17}$ valores de $\mathrm{HbF}$ de 7,61; e Gonçalves ${ }^{1}$ valores de 8,25\%.

Na comparação entre os haplótipos e as características hematológicas estudadas, apenas os valores de $\mathrm{HbF}$ e $\mathrm{Ht}$ apresentaram diferença estatisticamente significativa. (Tabela 2).

A concentração de $\mathrm{HbF}$ fetal é descrita como haplótipo dependente e diretamente correlacionada ao curso clínico da doença. ${ }^{18,19,20}$ Os níveis de $\mathrm{HbF}$ no haplótipo Bantu/Atípico $(10,88 \pm 2,78)$ foram superiores aos níveis dos haplótipos Bantu/Bantu $(6,14 \pm 3,46)$, Bantu/Benin $(6,47 \pm 3,59)$ e Benin/

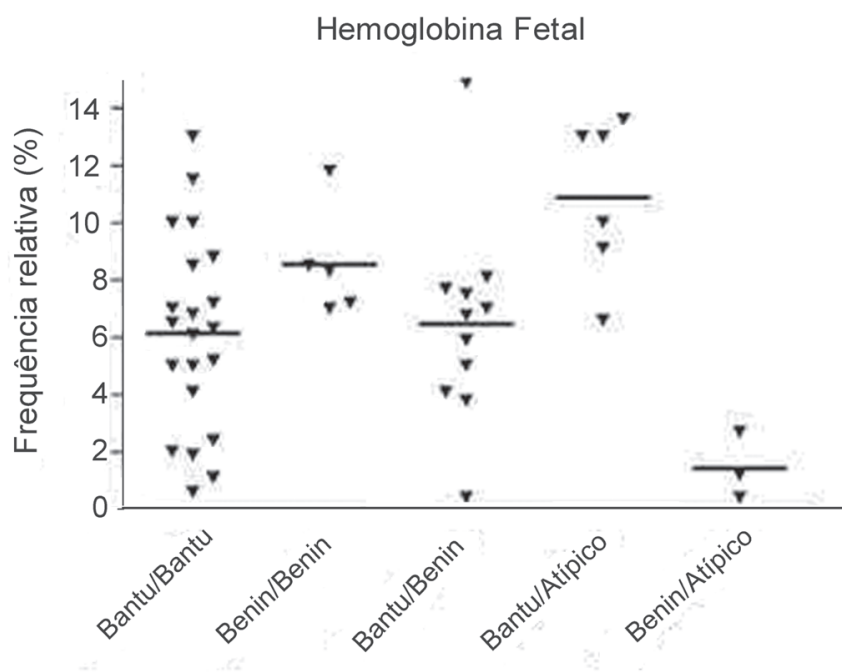

Haplótipos

Gráfico 1. Distribuição da média dos níveis de HbF nos diferentes haplótipos encontrados no estudo

Atípico (1,43 $\pm 1,17)$; e o haplótipo Benin/Benin $(8,56 \pm 1,93)$ apresentou níveis superiores em relação ao haplótipo Benin/ Atípico $(1,43 \pm 1,17)$. Esses resultados estão de acordo com os dados da literatura, que relata maiores níveis de hemoglobina fetal associados ao haplótipo Benin seguido do haplótipo Bantu. ${ }^{7,8}$

Os haplótipos atípicos foram encontrados associados aos haplótipos Bantu e Benin, indicando a ocorrência de diversos mecanismos genéticos que poderiam ser responsáveis pela variação das concentrações de $\mathrm{HbF}$ entre os portadores do haplótipo atípico, o que é demonstrado quando comparados os níveis de $\mathrm{HbF}$ dos haplótipos Bantu/Bantu (6,14 $\pm 3,46)$, Bantu/Atípico (10,88 $\pm 2,78)$; e haplótipos Benin/ $\operatorname{Benin}(8,56 \pm 1,93)$ e Benin/Atípico $(1,43 \pm 1,17) .{ }^{1,10,11,21}$

Em relação ao Ht, o haplótipo Bantu/Bantu $(25,98 \pm$ $2,86)$ apresentou níveis superiores ao haplótipo Bantu/Benin 
Tabela 3. Complicações clínicas dos pacientes de acordo com o haplótipo da anemia falciforme.

\begin{tabular}{|c|c|c|c|c|c|c|}
\hline & $\begin{array}{c}\text { Grupo } 1 \\
\text { Bantu/Bantu }\end{array}$ & $\begin{array}{c}\text { Grupo } 2 \\
\text { Benin/Benin }\end{array}$ & $\begin{array}{c}\text { Grupo } 3 \\
\text { Bantu/Benin }\end{array}$ & $\begin{array}{c}\text { Grupo } 4 \\
\text { Bantu/Atípico }\end{array}$ & $\begin{array}{c}\text { Grupo } 5 \\
\text { Benin/Atípico }\end{array}$ & $\begin{array}{c}\text { Grupos com } \\
\text { diferença estatística } \\
\text { (Valor de } p)\end{array}$ \\
\hline $\begin{array}{c}\text { Crises } \\
\text { vaso-oclusivas }\end{array}$ & $13 / 21(61,9 \%)$ & $3 / 5(60 \%)$ & $7 / 11(63,64 \%)$ & $1 / 6(16,67 \%)$ & $3 / 3(100 \%)$ & $\begin{array}{c}\text { Grupos } 4 \text { e } 5 \\
p=0,0476\end{array}$ \\
\hline $\begin{array}{l}\text { Transfusões de } \\
\text { hemácias }\end{array}$ & $19 / 21(90,48 \%)$ & $4 / 5(80 \%)$ & $7 / 11(63,64 \%)$ & $5 / 6(83,33 \%)$ & $2 / 3(66,67 \%)$ & $\underset{p>0,05}{N A}$ \\
\hline Pneumonia & $10 / 21(47,6 \%)$ & $2 / 5(40 \%)$ & $5 / 11(45,45 \%)$ & $1 / 6(16,67 \%)$ & $3 / 3(100 \%)$ & $\begin{array}{c}\text { Grupos } 4 \text { e } 5 \\
p=0,0476\end{array}$ \\
\hline Infecção urinária & 8/21(38,09\%) & $0 / 5(0 \%)$ & $4 / 11(36,36 \%)$ & $2 / 6(33,33 \%)$ & $3 / 3(100 \%)$ & $\begin{array}{c}\text { Grupos } 2 \text { e } 5 \\
p=0,0179\end{array}$ \\
\hline Litíase biliar & $10 / 21(47,6 \%)$ & $0 / 5(0 \%)$ & $3 / 11(27,27 \%)$ & $1 / 6(16,67 \%)$ & $1 / 3(33,33 \%)$ & $\underset{p>0,05}{N A}$ \\
\hline $\begin{array}{l}\text { Insuficiência } \\
\text { Cardíaca }\end{array}$ & $5 / 21(23,81 \%)$ & $1 / 5(20 \%)$ & $3 / 11(27,27 \%)$ & $1 / 6(16,67 \%)$ & $0 / 3(0 \%)$ & $\underset{p>0,05}{N A}$ \\
\hline $\begin{array}{c}\text { Acidente Vascular } \\
\text { Cerebral }\end{array}$ & $2 / 21(9,52 \%)$ & $0 / 5(0 \%)$ & $0 / 11(0 \%)$ & $0 / 6(0 \%)$ & $0 / 3(0 \%)$ & $\underset{p>0,05}{N A}$ \\
\hline Internação & $14 / 21(66,67 \%)$ & $3 / 5(60 \%)$ & $7 / 11(63,64 \%)$ & $1 / 6(16,67 \%)$ & $3 / 3(100 \%)$ & $\underset{p>0,05}{N A}$ \\
\hline Úlceras de perna & $6 / 21(28,57 \%)$ & $1 / 5(20 \%)$ & $4 / 11(36,36 \%)$ & $0 / 6(0 \%)$ & $1 / 3(33,33 \%)$ & $\underset{p>0,05}{N A}$ \\
\hline Necrose no fêmur & $5 / 21(23,81 \%)$ & $0 / 5(0 \%)$ & $0 / 11(0 \%)$ & $0 / 6(0 \%)$ & $0 / 3(0 \%)$ & $\begin{array}{c}N A \\
p>0,05\end{array}$ \\
\hline
\end{tabular}

Fonte: Dados da pesquisa, 2009.

Os resultados das manifestações clínicas foram reportados para cada haplótipo em valores de n/total (\%), ou seja, no número de pacientes em que ocorreu o evento dividido pelo total de pacientes (porcentagem). O teste utilizado para comparação de proporções entre os grupos foi o teste Exato de Fisher. NA- Não aplicável, pois não houve diferença entre os grupos.

$(22,54 \pm 3,19)$, o que corresponde com os resultados encontrados por Galiza Neto et al. ${ }^{17}$ Resultados diferentes foram encontrados por Fleury ${ }^{22}$ e Gonçalves et al. ${ }^{1}$ A correlação entre os níveis de $\mathrm{Ht}$ e os haplótipos não tem sido foco de muitas pesquisas, pois não há relatos na literatura que evidenciem a influência dos haplótipos no volume globular das hemácias.

Estudos anteriores sugerem que o haplótipo Bantu está associado a uma maior incidência de complicações clínicas do que o haplótipo Benin . 1,7,8,23,24 Em nosso estudo houve diferença estatisticamente significativa apenas entre os haplótipos Bantu/Atípico e Benin/Atípico em relação à presença de crises vaso-oclusivas e episódios de pneumonia; e entre Benin/Atípico e Benin/Benin em relação às crises de infecção urinária (Tabela 3). Foi demonstrada maior presença de crises vaso-oclusivas e episódios de pneumonia no haplótipo Benin/Atípico do que no haplótipo Bantu/Atípico; e maior presença de crises de infecção urinária no haplótipo Benin/Atípico do que no haplótipo Benin/Benin. Os haplótipos atípicos em heterozigose com os haplótipos Bantu e Benin podem ser responsáveis pela variação na presença das complicações clínicas do nosso estudo em relação aos dados da literatura. ${ }^{1,10,11,21}$

Não houve diferença estatisticamente significativa entre os haplótipos Bantu/Bantu e Benin/Benin em relação às complicações clínicas, entretanto foi observado que o haplótipo Bantu/Bantu tem uma maior frequência em todos os eventos clínicos estudados quando comparado ao Benin/ Benin. Foi encontrado um pequeno número de pacientes com o haplótipo Benin/Benin no estudo, o que pode ter levado a resultados sem diferença significativa na comparação de proporções entre estes grupos.

Os resultados demonstram que o tipo de haplótipo do gene da $\beta^{\mathrm{S}}$ - globina influencia as características fenotípicas dos pacientes com anemia falciforme, portanto a utilização de técnicas moleculares para a detecção do haplótipo envolvido deve ser considerada como uma importante ferramenta diagnóstica para prever o quadro clínico destes pacientes.

\footnotetext{
Abstract

We analyzed 47 patients living in Fortaleza, Ceará with clinical, laboratory and molecular diagnosis of sickle cell anemia, in order to provide information on the influence of the $\beta^{S}$-globin gene haplotypes on the phenotypic characteristics of this disease. The evaluation of hematological values was performed using an automated blood cell counter and the levels of $\mathrm{HbF}$ were determined by the alkali denaturation technique. The DNA was isolated from leukocytes from a whole blood sample. The analysis of the haplotypes of the $\beta S$ mutation was achieved by PCR-RFLP, with an assessment of six polymorphic restriction sites. The patients were divided in 5 groups according to the type of haplotype: Bantu/Bantu, Benin/Benin,
} 
Bantu/Benin, Bantu/Atypical and Benin/Atypical. The level of significance was set for a p-value $<0.05$. In the comparison between the haplotypes and the hematological characteristics, statistically significant differences were seen only for the values of $\mathrm{HbF}$ and Ht. The levels of $\mathrm{HbF}$ were higher for the Benin haplotype, followed by the Bantu haplotype, which is in agreement with the literature. There were more painful episodes and pneumonia in Benin/Atypical haplotype than in Bantu/Atypical patients, and a higher rate of urinary tract infection in Benin/Atypical haplotype than in Benin/Benin haplotype individuals. There was no statistically significant difference between the Bantu/Bantu and Benin/Benin haplotypes in respect to clinical complications however the Bantu/ Bantu haplotype was associated to a higher frequency in all studied clinical events when compared to Benin/Benin haplotype patients. The results show that the type of $\beta^{\text {s}}$-globin gene haplotype influences the phenotypic characteristics of patients with sickle cell anemia, therefore molecular techniques should be considered to identify the haplotype as an important diagnostic tool to predict the clinical status of these patients. Rev. Bras. Hematol. Hemoter.

Key words: Anemia; sickle cell; phenotype; prognosis; genetica.

\section{Referências Bibliográficas}

1. Gonçalves MS, Bonfim GC, Maciel E, et al. BetaS-Haplotypes in sickle cell anemia patients from Salvador, Bahia, Northeastern Brazil. Braz J Med Biol Res. 2003;36(10):1283-8.

2. Bonini-Domingos CR. Metodologias laboratoriais para o diagnóstico de hemoglobinopatias e talassemias. Brasil: HN, Inc. 121 p., 2006.

3. Antonarakis SE, Kazazian HH, Orkin SH. DNA polymorphism and molecular pathology of the human globin gene clusters. Hum Genet. 1985;69(1):1-14.

4. Zago MA. Considerações gerais. In: Anvisa (Agência Nacional de Vigilância Sanitária). Manual de diagnóstico e tratamento de doenças falciformes. Brasil: Copyright. 2002. p 7-12.

5. Steinberg M. Modulation of fetal hemoglobin in sickle cell anemia. Hemoglobin. 2001;25(2):195-211.

6. Adorno EV, Zanette A, Lyra I, Seixas MO, Reis MG, Gonçalves MS. Clinical and molecular characteristics of sickle cell anemia in the northeast of Brazil. Genet Mol Biol. 2008;31:621-5.

7. Nagel RL. The origin of the hemoglobin $S$ gene: clinical, genetic and anthropological consequences. Einstein Quarterly Journal of Biology and Medicine. 1984;2:53-62.

8. Powars DR. Beta-s-gene-cluster haplotypes in sickle cell anemia. Clinical and hematological features. Hematol Oncol Clin North Am. 1991;5(3):475-93.

9. Sutton M, Bouhassira EE, Nagel RL. Polymerase chain reaction amplification applied to the determination of beta-like globin gene cluster haplotypes. Am J Hematol. 1989;32(1):66-9.

10. Zago MA, Silva WA Jr, Gualandro S, Yokomizu IK, Araujo AG, Tavela $\mathrm{MH}$, et al. Rearrangements of the beta-globin gene cluster in apparently typical betaS haplotypes. Haematologica. 2001;86 (2):142-5

11. Zago MA, Silva WA, Dalle B, et al. Atypical beta (s) haplotypes are generated by diverse genetic mechanisms. Am J Hematol. 2000; 63(2):79-84.

12. Betke K, Marti NR, Schlicht I. Estimation of small percentages of foetal haemoglobin. Nature. 1959;184(Suppl 24):1877-8.
13. Sambrook J, Fritsch EF, Maniats T. Molecular cloning: a laboratory manual. New York: Cold Spring Harbor Laboratory Press, 1989.

14. Sutton M, Bouhassira EE, Nagel RL. Polymerase chain reaction amplification applied to the determination of beta-like globin gene cluster haplotypes. Am J Hematol. 1989;32(1):66-9.

15. Queiroz IMLP. Características clínicas, hematológicas e genéticas em pacientes homozigotos para a hemoglobinopatia $\mathrm{S}$ da Bahia e de São Paulo. 1996. 111f. Dissertação (Mestrado em Hematologia)Universidade Federal de São Paulo, São Paulo, 1996.

16. Figueiredo MS, Kerbauy J, Gonçalves MS, Arruda VR, Saad ST, Sonati MF, et al. Effect of alpha-thalassemia and beta-globin gene cluster haplotypes on the hematological and clinical features of sickle-cell anemia in Brazil. Am J Hematol. 1996;53(2):72-6.

17. Galiza Neto GC, Pitombeira MS, Vieira HF, Vieira MLC, Farias DAB. Análise dos haplótipos do gene da beta S-globina no Ceará. Jornal Brasileiro de Patologia e Medicina Laboratorial. 2005;41: 315-21.

18. Gilman JC, Huisman THJ. DNA sequence variation associated with elevated fetal 'y globin production. Blood. 1985;66(78):783-87.

19. Powars DR. Natural history of sickle cell disease: The first ten years. Semin Hematol. 1975;12(3):267-85.

20. Steinberg MH. Management of sickle cell disease. New Engl. J. Med. 1999;340(13):1021-30.

21. Bordin S, Crespi VG, Duarte AS, Basseres DS, Melo MB, Vieira AP, et al. DNAse I hypersensitive site 3 to the beta-globin gene cluster contains a TAA insertion specific for beta (S)-Benin haplotype. Haematologica. 2002;87(3):246-9.

22. Fleury MK. Haplotypes of beta-globin gene in sickle cell anemia patients of Rio de Janeiro, Brazil. Rev. Bras. Hematol. Hemoter. 2001;23:57-8

23 Adorno EV, Zanette A, Lyra I, Souza CC, Santos LF, Menezes JF, et al. The beta-globin gene cluster haplotypes in sickle cell anemia patients from Northeast Brazil: a clinical and molecular view. Hemoglobin. 2004;28(3):267-71.

24. Steinberg M. Modulation of fetal hemoglobin in sickle cell anemia. Hemoglobin. 2001;25(2):195-211.

Avaliação: Editor e dois revisores externos

Conflito de interesse: sem conflito de interesse

Recebido:27/04/2009

Aceito após modificações: 05/07/2009 